\title{
L'obsolescence déprogrammée : Fablabs, makers et repair cafés
}

Prendre le parti des choses pour prendre le parti des hommes

De-Programming Obsolescence: Fablabs, Makers and Repair Cafés

\section{Marie Goyon}

\section{OpenEdition}

\section{Journals}

Édition électronique

URL : https://journals.openedition.org/tc/7981

DOI : $10.4000 /$ tc. 7981

ISSN : $1952-420 X$

\section{Éditeur}

Éditions de l'EHESS

Édition imprimée

Date de publication : 31 octobre 2016

Pagination : 236-239

ISBN : 9782713225291

ISSN : 0248-6016

\section{Référence électronique}

Marie Goyon, «L'obsolescence déprogrammée: Fablabs, makers et repair cafés », Techniques \& Culture [En ligne], 65-66 | 2016, mis en ligne le 31 octobre 2016, consulté le 29 septembre 2022. URL : http:// journals.openedition.org/tc/7981 ; DOI : https://doi.org/10.4000/tc.7981 


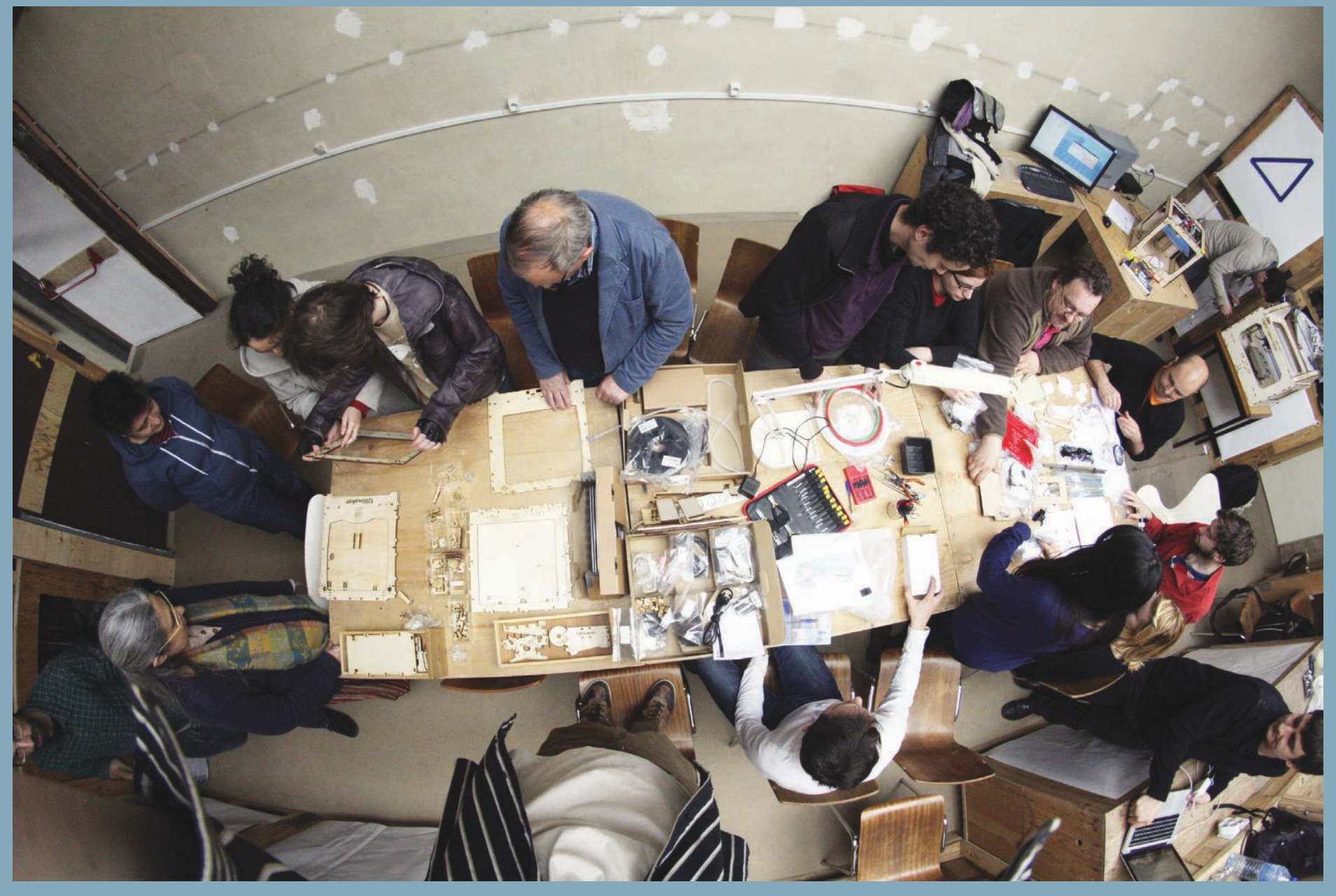




\section{I'obsolescence déprogrammée: Fablabs, makers et repair cafés}

\section{Prendre le parti des choses pour prendre le parti des hommes}

Il est établi que les objets ont une vie sociale et sensible dont on peut retracer le parcours biographique (Appadurai 1986). Ils ont parfois une «seconde vie» par l'intermédiaire de dispositifs divers, du recyclage au marché de la «seconde main ».

Dans le cadre de cet article, c'est plus précisément la dimension politique de la seconde vie des objets qui est interrogée, à travers la réparation et le bricolage, au sein du mouvement des fablabs, des makers et des repair cafés. S'ils peuvent se différencier par le profil des acteurs, les localisations et les trajectoires historiques, les lieux associatifs issus de ce mouvement semblent avoir en commun de développer une forme d'utopie sociale, interrogeant la question des transferts d'expériences et de savoir-faire entre de traditionnels experts de la conception et de la fabrication (ingénieurs et designers en particulier) et le « grand public», à travers un mouvement qui prône la participation et l'open source. Une dimension proprement anthropologique, dans le rapport au corps et à l'expérience du «faire», semble se développer, en même temps qu'une alternative économique, qualifiée par certains de «troisième révolution industrielle » (Anderson 2012, Rifkin 2013), ou encore l'avènement d'un «âge du faire», par l'invention d'un nouveau modèle d'activité (Lallement 2015).

Entrons-nous dans une ère placée sous le signe du «sacre de l'amateur (Flichy 2010), du «néoartisanat », à travers des pratiques ayant le vent en poupe telles que le DIY (Do It Yourself)? Outre une expansion économique du bricolage marchand, on observe en effet une multiplication des initiatives vouées au bricolage comme art de la réparation, de l'économie budgétaire et ressourcielle. Certaines œuvrent pour la prolongation de la vie des objets et la lutte contre le « gâchis » et l'«obsolescence programmée». Nous nous attardons sur celles-ci et verrons qu’elles sont encouragées et soutenues par nos institutions politiques (certains partis et politiques gouvernementales, notamment) et qu'elles prennent place dans des organisations dites «citoyennes», aux deux sens du terme, c'est-à-dire à l'initiative des citoyens et, au sens éthique et politique, orientées vers le bien commun de la Cité. 
La réflexion que nous engageons ici est à ses débuts. Elle s'appuie d'une part sur les sites internet des initiatives «fablabs», «makers » et « repair» et d'autre part sur les observations et entretiens ethnographiques préliminaires, réalisés auprès de la Fabrique d'Objets Libres, fablab associatif lyonnais, dans le cadre de son Laboratoire de l'Obsolescence Déprogrammée.

Cependant, ce travail exploratoire permet déjà d'avancer des pistes prometteuses. Après un rapide portrait sociologique des participants, nous nous attardons sur la trajectoire des objets obsolescents. Des opérations de qualification de leur «potentiel» dans le cadre de la «ressourcerie» sont observées. Les changements de statut accordés aux objets et pièces se voient donner un sens politique par les acteurs, en tant qu'affirmation d'une émancipation vis-à-vis des «systèmes marchands» et de la «dictature technologique», en vue d'une «libération» des objets (expressions ad hoc). On décrit les discours et manipulations lors des arbitrages sur leur devenir, au cours de la «bidouille» (terme emic que nous nous attachons à définir). On observe ainsi leur « retape», voire leur transformation dans le cadre d'une démarche dite d'«intervention» par « rétroconception» et de «up»-cycling.

Cette relation entretenue avec les objets vient, selon nous, apporter un éclairage original pour l'anthropologie de la culture matérielle, du corps et des techniques, interrogeant en particulier l'essor d'une certaine forme de «démocratie technique» (Callon, Lascoumes \& Barthe 2001) alliant low tech (objets du quotidien comme des perceuses, cafetières, fers à repasser...) et high tech (les machines et savoirs, informatique, imprimante 3D, découpes laser. ..). Ainsi, certains acteurs adoptent une posture très politique: ils considèrent que la relation directe à l'objet et à la technique permet non seulement la critique, mais plus encore la transformation sociale du monde et, en premier lieu, des individus.

En effet, nous avons constaté que l'expérience des bidouilleurs constitue moins un savoirfaire, qu'un pouvoir-faire. S'il s'agit en partie d'une tentative de réhabilitation des «vertus artisanales» contre l'univers du management et de la segmentation entre le travail et son sens, dans la veine des thèses développées par Crawford (2010) ou Sennett (2010), celle-ci porte principalement sur l'idée de relation directe aux techniques et à l'action. Ce constat nous pousse donc à interroger la nature de la démocratisation que prétendent faire émerger les mouvements du make. Hormis pour les fabmanagers (animateurs des fablabs, nouvelle catégorie d'experts techniques), l'expertise retirée par le plus grand nombre semble finalement moins technique que sociale. Il s'agirait même davantage d'une expérience qui conduirait à une compétence à «oser faire», à sortir d'une certaine culture de la délégation technique.

La «bidouille» procède ainsi d'un plaisir subversif à sortir de la sujétion: on reprend le pouvoir sur -mais surtout avec les choses, en s'autorisant à les ouvrir, démanteler, transformer. Ainsi, prendre le parti des «choses» semble un moyen efficace de prendre le parti des hommes, sous la forme d'une « désobéissance technologique» (Oroza 2009) qui s’accompagne d'une désobéissance économique et idéologique. Dans la mesure où la popularisation de ce mouvement s'étend, il pourrait constituer, selon les points de vue, une menace ou une promesse réelle d'un point de vue politique. 


\section{En ligne}

Retrouver l'article complet sur revues.org, TechniquesECulture 65-66 « Réparer le monde» : http:// tc.revues.org/

\section{I'auteure}

Marie Goyon est anthropologue, enseignante-chercheure à l'École Centrale de Lyon, membre de l'UMR CNRS EVS5600. Responsable des Sciences humaines et sociales pour le Programme IDEA (Innovation, Design, Entreprenariat et Arts), ses recherches portent sur la place du corps dans l'apprentissage et la transmission des savoir-faire artistiques (Amérique du Nord) et techniques, ainsi que sur les enjeux sociopolitiques de la culture matérielle, des savoirs et conceptions

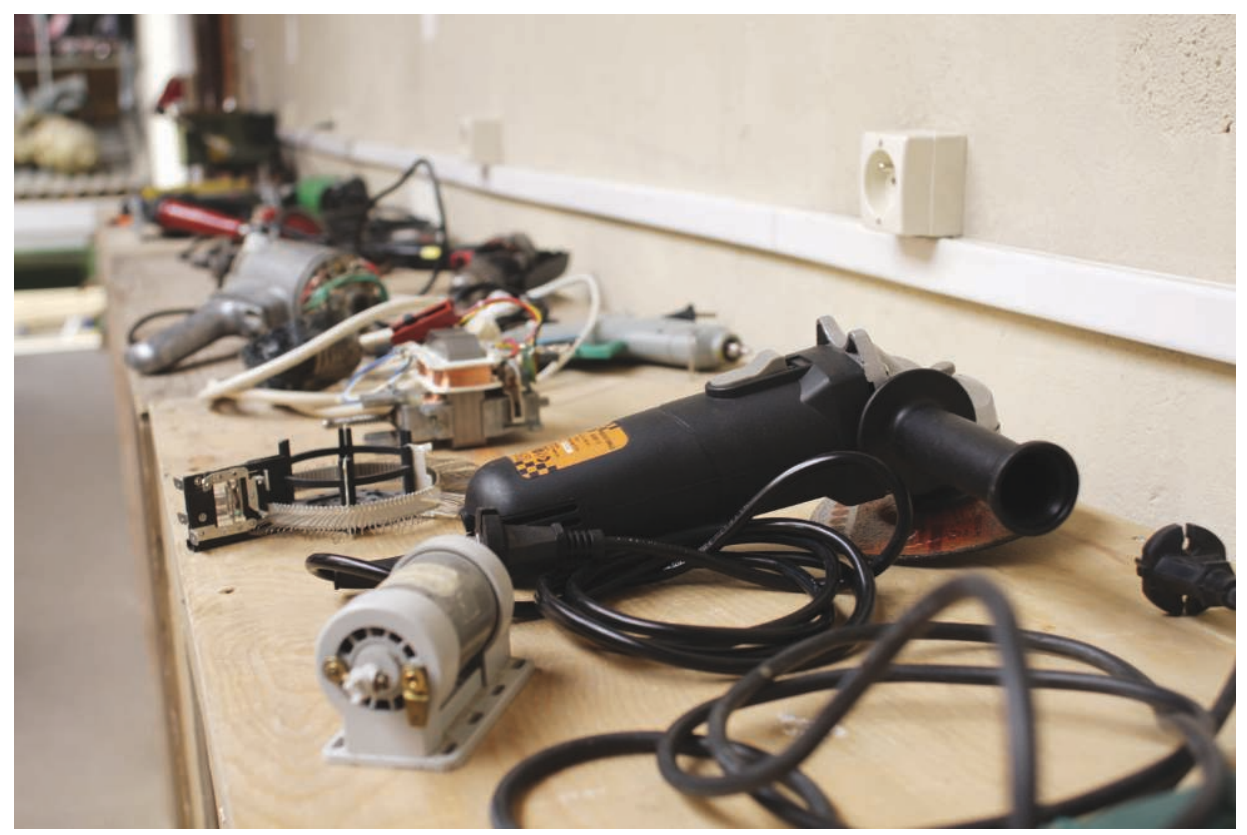
techniques (terrains actuels : robotique et fablabs).

1. Atelier LOD.

Déchets-objets, perceuses.

\section{Références}

Anderson, C. 2012 Makers. La nouvelle révolution industrielle. Paris: Pearson.

Appadurai, A. dir. 1986 The Social Life of Things: Commodities in Cultural Perspective. Cambridge Mass.: Cambridge University Press.

Callon, M., Lascoumes, P. \&Y. Barthe 2001 Agir dans un monde incertain. Essai sur la démocratie technique. Paris: Seuil.

Crawford, M. 2010 Éloge du carburateur. Essai sur le sens et la valeur du travail. Paris: La Découverte.

Flichy, P. 2010 Le sacre de l'amateur. Sociologie des passions ordinaires à l'ère numérique. Paris: Seuil.

Lallement, M. 2015 L'âge du faire. Hacking, travail, anarchie. Paris: Seuil.

Oroza, E. 2009 Rikimbili. Une étude sur la désobéissance technologique et quelques formes de réinvention. Saint-Étienne: Publications de l'Université de Saint-Étienne - Cité du Design.

Rifkin, J. 2013 La troisième révolution industrielle. Comment le pouvoir latéral va transformer l'énergie, l'économie et le monde. Paris: Actes Sud.

Sennett, R. 2010 [2008] Ce que sait la main. La culture de l'artisanat. Paris: Albin Michel.

\section{Iconographie}

Image d'ouverture. Atelier imprimante 3D, FOL Lyon. (c) FOL, CC, Dimitri Ferrière.

1. C FOL, CC, Dimitri Ferrière.

\section{Pour citer cet article:}

Goyon, M. 2016 «L’obsolescence déprogrammée: Fablabs, makers et repair cafés. Prendre le parti des choses pour prendre le parti des hommes», TechniquesE Culture 65-66 «Réparer le monde. Excès, reste et innovation », p. 236-239. 